\title{
Foliar Application of Cytokinin Modulates Gas Exchange Features, Water Relation and Biochemical Responses to Improve Growth Performance of Maize under Drought Stress
}

\author{
M. Rafiqul Islam ${ }^{1,}$, M. Shahinur Islam ${ }^{1}$, Nurunnaher Akter ${ }^{1}$, Mohammed Mohi-Ud-Din ${ }^{2}$ and \\ Mohammad Golam Mostofa ${ }^{3,4, *}$
}

${ }^{1}$ Department of Agronomy, Bangabandhu Sheikh Mujibur Rahman Agricultural University, Gazipur, 1706, Bangladesh

${ }^{2}$ Department of Crop Botany, Bangabandhu Sheikh Mujibur Rahman Agricultural University, Gazipur, 1706, Bangladesh

${ }^{3}$ Department of Biochemistry and Molecular Biology, Bangabandhu Sheikh Mujibur Rahman Agricultural University, Gazipur, 1706, Bangladesh

${ }^{4}$ Institute of Genomics for Crop Abiotic Stress Tolerance, Department of Plant and Soil Science, Texas Tech University, Lubbock, TX 79409, USA

*Corresponding Authors: Mohammad Golam Mostofa. Email: mmostofa@ttu.edu; mostofa@bsmrau.edu.bd; M. Rafiqul Islam. Email: rafiarib@yahoo.com

Received: 27 June 2021 Accepted: 30 August 2021

\begin{abstract}
Improvement of plant performance under drought stress is crucial to sustaining agricultural productivity. The current study investigated the ameliorative effects of foliar-applied kinetin, an adenine-type cytokinin (CK), on growth and gas exchange parameters, water relations and biochemical attributes of maize plants under drought stress. Eighteen-day-old maize plants were subjected to drought by maintaining soil moisture content at $25 \%$ field capacity for 8 days followed by foliar application of kinetin at $0,75,150$ and $225 \mathrm{mg} \mathrm{L}^{-1}$ (CK0, CK75, CK150 and CK225, respectively) to the plants for two-times at the 9-day interval. Results revealed that drought stress markedly reduced stem diameter, dry weight, chlorophyll content, gas exchange parameters and water balance but increased proline, malondialdehyde and soluble sugar contents, electrolyte leakage and senescence in maize leaves. Application of exogenous CK remarkably improved maize performance by modulating growth, gas exchange- and water relation-related parameters in a dose-dependent manner under drought stress. CK225 increased chlorophyll content (by 61.54\%), relative water content (by 49.14\%), net photosynthesis rate (by 39.94\%) and transpiration rate (by 121.36\%) and also delayed leaf senescence but decreased internal $\mathrm{CO}_{2}$ concentration (by 7.38\%), water saturation deficit (by 40.40\%) and water uptake capacity (by $42.49 \%$ ) in both well-watered and droughtstressed plants. Nevertheless, CK application considerably decreased electrolyte leakage, proline, malondialdehyde and soluble sugar levels in drought-stressed maize plants, as also supported by heatmap and cluster analyses. Taken together, exogenous $\mathrm{CK}$ at proper concentration $\left(225 \mathrm{mg} \mathrm{L}^{-1}\right)$ successfully improved maize performance under drought conditions, thereby suggesting CK application as a useful approach to alleviate drought-induced adverse effects in maize plants, and perhaps in other important crop plants.
\end{abstract}

\section{KEYWORDS}

Cytokinin; drought; maize; osmoprotection; photosynthesis; water-use-efficiency 


\section{Introduction}

Maize (Zea mays) is a promising cereal crop for achieving global food security [1]. Drought, an intricate abiotic stress, is a major constraint for the intensification and sustainability of maize production worldwide [2]. It is estimated that a single episode of drought costed 7\% global yield loss in maize, which is predicted to be increased in the future due to climate change [3]. In South Asia, most of the agricultural lands (65\%) are frequently exposed to differential degrees of periodic drought, which is responsible for $10-15 \%$ yield loss every year in this region [4,5]. In the southwestern and northwestern regions of Bangladesh, 51\% $\left(17,243 \mathrm{~km}^{2}\right)$ areas are extremely vulnerable to drought [6]. The simulated models estimated an increase in yield loss from 9.0 to $12.0 \%$ and $5.6 \%$ to $6.3 \%$ for wheat and maize, respectively, by the end of the $21^{\text {st }}$ century [7]. However, maize is more sensitive to drought than wheat, particularly during the reproductive stage [2]. Thus, finding effective mitigation strategies, including sustainable adaptation practices are required to address drought effects on maize growth and productivity.

Drought negatively affects plant growth and development, resulting in yield loss to a number of crops, including maize $[8,9]$. Drought stress causes abnormal changes in morphology, water status, gas exchange, and chlorophyll content in plants [10,11]. Plants also respond to water shortage by accommodating various physiological, biochemical and molecular changes, leading to adaptation to drought stress [12]. Currently, there are hardly any economically viable technologies available to facilitate maize production under water-shortage conditions. However, agronomic manipulations, including the application of exogenous plant growth regulators are considered promising approaches for improving maize growth and development, thereby contributing to sustainable maize production under drought-stressed environments $[13,14]$.

Drought can adversely affect root and shoot growth by disrupting endogenous levels of phytohormones [15]. Thus, maintaining hormonal balance is crucial to support plant growth under adverse environmental conditions. A wealth of studies demonstrated that application of exogenous phytohormones, including cytokinin (CK) boosted plant tolerance to drought stress by modulating numerous physiological and biochemical functions of plants [16]. Cytokinins (CKs) are multifunctional phytohormones that control cell proliferation and vascular development, root function and nodulation, and promote apical dominance, all of which govern plant growth processes under both normal and stressed situations [7,17-19]. Being a growth regulator, $\mathrm{CK}$ is involved in several fundamental aspects of plant development and stress tolerance [20,21]. Application of exogenous CK improved plant growth by regulating many key processes of plant like cell division and expansion [22-24] photosynthesis and stomatal behavior [25,26], biogenesis of chloroplasts and senescence [27,28], water exchange and ion uptake [29], formation and protection of cellular structures [30], the induction and activation of osmoprotectants and antioxidant systems [31]. The positive effects of CK application have been reported in many plant species, including wheat (Triticum aestivum), barley (Hordeum vulgare), mungbean (Vigna radiata) and faba bean (Vicia faba) under different environmental stress conditions [32-35]. However, the putative roles of CK in alleviating drought stress in maize were not thoroughly investigated.

In the current study, we investigated the beneficial roles of CK in the improvement of maize performance under drought stress conditions. For this purpose, we evaluated CK-mediated drought tolerance mechanisms at the physiological and biochemical levels by analyzing several growth-related parameters, gas exchange properties, osmoprotection, water status and membrane damage in maize. We also searched for the effective concentration of $\mathrm{CK}$ needed for enhanced maize performance under greenhouse settings with restricted water supply. 


\section{Materials and Methods}

\subsection{Experimental Site, Plant Material and Plant Growth Conditions}

The experiment was conducted under semi-controlled environmental condition in the Stress Research Site of the Department of Agronomy, Bangabandhu Sheikh Mujibur Rahman Agricultural University $\left(90.26^{\circ} \mathrm{E}\right.$ and $\left.24.09^{\circ} \mathrm{N}\right)$, Gazipur, Bangladesh during the period from July to September 2014 using a widely used variety BARI maize-5 developed by Bangladesh Agricultural Research Institute (BARI). A total of 48 wagoner pots $(25 \mathrm{~cm}$ diameter and $30 \mathrm{~cm}$ height $)$ were taken to carry out the study. Soil used in the experiment was sandy clay loam that attained the full field capacity at $27.8 \%$ volumetric water content. Three seeds of maize were sown directly in plastic pots containing $12 \mathrm{~kg}$ of soil and organic compost $(3: 1, \mathrm{v} / \mathrm{v})$ under the conditions of $12.3 / 11.7 \mathrm{~h}$ light/dark period. Chemical fertilizers, including urea, triple super phosphate, muriate of potash and gypsum were applied as per recommendation of BARC [36]. Most of the seedlings emerged within 5-6 days of sowing. The pots were thinned to one healthy plant per pot at 8 days after emergence (DAE). Two sets of pots of which Set-1 containing 24 plants was selected for drought treatments, whereas Set-2 containing 24 plants was kept for well-watered (WW) treatments.

\subsection{Imposition of Drought and Hormonal Treatments}

Both sets of pots were properly irrigated to ensure better growth of the plants. Eighteen-day-old plants of Set-1 were subjected to drought by withdrawing regular irrigation and then maintaining $25 \%$ field capacity (approximately $7 \%$ volumetric moisture content) for a period of 8 days. On the other hand, the soil moisture contents of Set-2 pots containing WW plants were maintained at full field capacity (approximately 27.8\% volumetric moisture content). The soil moisture levels at $15 \mathrm{~cm}$ depth of all the experimental pots were carefully monitored every day using a digital soil moisture meter (PMS-714, Lutron Electronic Enterprise Co., Ltd., Taiwan) throughout the experimental period. Kinetin, an adenine-type CK, was used as an exogenous source of CK. After the drought period, both drought-stressed and WW plants were foliarsprayed with different concentrations of kinetin $\left(0,75,150\right.$ and $225 \mathrm{mg} \mathrm{L}^{-1}$, hereafter defined as CK0, CK75, CK125 and CK225, respectively) at 26 DAE and 35 DAE. The experiment consisted of eight treatments, including (i) control (well-watered, WW) (CK0), (ii) $\mathrm{WW}+75 \mathrm{mg} \mathrm{L}^{-1}$ kinetin (CK75), (iii) $\mathrm{WW}+150 \mathrm{mg} \mathrm{L}^{-1}$ kinetin (CK150); (iv) WW + $225 \mathrm{mg} \mathrm{L}^{-1}$ kinetin (CK225); (v) drought stress (DS); (vi) DS + CK75; (vii) DS + CK150 and (viii) DS + CK225. All the treated and untreated plants were allowed to grow until final harvest at 51 DAE for determinations of dry weight, gas exchange parameters, leaf chlorophyll contents, water status and biochemical parameters. The experiment was laid out in a randomized complete block design with six replications $(n=6)$ and each replicate included one plant (i.e., 6 plants per treatment). There was total 48 pots $(6$ pots $\times 8$ treatments $=48)$ in the current study.

\subsection{Measurement of Growth Parameters, Gas Exchange Properties and Water Status}

Growth related parameters, such as stem diameter, leaf senescence, fresh weight (FW), dry weight (DW) of different plant parts, including roots, stems and leaves were determined following the procedure reported by Akter et al. [13] and Borras et al. [37]. Leaf gas exchange parameters like net photosynthetic rate $(\mathrm{Pn})$, stomatal conductance (gs), transpiration rate ( $\mathrm{Tr}$ ) and intercellular $\mathrm{CO}_{2}$ concentration (Ci) were recorded in fully developed and expanded third leaf from the top of each plant at $11.30 \mathrm{am}$ to $12.30 \mathrm{pm}$ of the local time using the portable photosynthesis measurement system Li 6400XT (Model-Li 6400XT, LI-COR Inc., Lincoln, NE, USA). Water relation traits, including leaf relative water content (RWC), and water saturation deficit (WSD) and water uptake capacity (WUC) were measured in maize leaves following the protocols reported by Schonfeld et al. [38] and Sangakkara et al. [39], respectively. The RWC, WSD and WUC were calculated based on the following formulae: RWC $(\%)=[(\mathrm{FW}-\mathrm{DW}) /(\mathrm{TW}-\mathrm{DW})] \times 100 ; \mathrm{WSD}(\%)=[(\mathrm{TW}-\mathrm{FW}) /(\mathrm{TW}-\mathrm{DW})] \times 100 ; \mathrm{WUC}=(\mathrm{TW}-\mathrm{FW}) /$ DW, where, FW, fresh weight; DW, dry weight and TW, turgid weight $[38,39]$. 


\subsection{Estimation of Total Chlorophyll Content in Maize Leaves}

Total chlorophyll contents in the leaf samples were measured following the procedure of Witharn et al. [40] by using double beam spectrophotometer (Model 200-20, Hitachi, Japan). Twenty mg of leaf sample was collected in a bottle containing $20 \mathrm{~mL}$ acetone and kept in bottle for $48 \mathrm{~h}$. The absorbance of the supernatants was spectrophotometrically read at 645 and $663 \mathrm{~nm}$ using $80 \%$ acetone as blank. Total chlorophyll content was calculated using the formula adopted by Witharn et al. [40].

\subsection{Determination of Proline and Total Soluble Sugar Contents in Maize Leaves}

Proline content was determined following the procedure of Bates et al. [41]. Briefly, fresh leaf samples $(0.5 \mathrm{~g})$ were crushed in $3 \%$ sulfosalicylic acid solution and allowed to settle for $5 \mathrm{~min}$. After centrifugation at $15,500 \mathrm{~g}, 2 \mathrm{~mL}$ of filtrate was mixed with $2 \mathrm{~mL}$ each of acid ninhydrin glacial acetic acid solution. The mixture was heat at $100{ }^{\circ} \mathrm{C}$ for $60 \mathrm{~min}$ followed by cooling on ice bath for $30 \mathrm{~min}$. Toluene was used to collect the chromophore, and the absorbance of the collected solution was read at $520 \mathrm{~nm}$ using toluene as blank. Proline content was determined from a standard graph developed with a series of proline concentrations. Total soluble sugar content was determined using anthrone reagent following the procedure developed by Kirankumari et al. [42].

\subsection{Measurement of MDA and Electrolyte Leakage in Maize Leaves}

The level of MDA was determined using thiobarbituric acid (TBA)-dependent method of Health et al. [43]. MDA content in leaf samples was calculated using an extinction coefficient of $155 \mathrm{~m} \mathrm{M}^{-1} \mathrm{~cm}^{-1}$. Drought injury index or electrolytic leakage (EL) was tested following the method reported by Kocheva et al. [44]. Briefly, 20 leaf discs (size of the disc) of drought-stressed and -unstressed plants were washed with distilled water to clean the disc. The disc samples were then immersed in $20 \mathrm{~mL}$ distilled water at room temperature. After $24 \mathrm{~h}$, the conductivity of the solutions ( $\mathrm{Lt}$ ) was read using a conductivity meter. The samples were autoclaved at $120^{\circ} \mathrm{C}$ for $15 \mathrm{~min}$ followed by cooling at room temperature for $20 \mathrm{~min}$. The conductivity of the resultant solutions was read again (Lo). The EL was calculated using the following formula: EL $(\%)=(\mathrm{Lt} / \mathrm{Lo}) \times 100$.

\subsection{Statistical Analysis}

Analysis of variance was conducted using MSTAT-C software [45] and significant difference among the means was compared by post-hoc least significant difference (LSD) test at $P<0.05$. Heatmap and cluster analysis were carried out using R-4.1.0 for win (http://CRAN.R-project.org/) (accessed on 25 June 2021). Trait mean values were normalized and the library pheatmap was adapted for generating heatmap and hierarchical clusters $($ distance $=$ Euclidean and method $=$ ward. D2 [46].

\section{Results}

\subsection{Effects of CK on Growth Associated Attributes of Maize under Drought Stress}

Growth parameters, such as, DW of root, stem and leaf were determined to evaluate the effects of CK in the alleviation of drought effects on maize growth and development. Drought stress negatively affected plant biomass by reducing root DW (74.21\%), stem DW (81.90) and leaf DW (69.69\%) in comparison with those observed in maize plants under WW conditions (Table 1). However, the application of exogenous CK significantly increased the dry biomass of root, stem and leaf in both control and drought-stressed plants when contrasted with their respective controls. Particularly, application of CK225 to drought exposed maize plants increased root DW, stem DW and leaf DW by $52.00 \%, 71.59 \%$ and $73.00 \%$, respectively, relative to drought-stressed only plants (Table 1). Under non-stressed conditions, CK225 also increased 
root DW, stem DW and leaf DW by $15.67 \%, 24.12 \%$ and $29.68 \%$, respectively, in control plants. Interestingly, dry biomass accumulation increased with the increase of $\mathrm{CK}$ concentration and CK225 showed the most effective roles in counteracting the adverse effects of drought on maize growth (Table 1).

Table 1: Effect of foliar-applied cytokinin (CK) on dry matter accumulation in maize plants

\begin{tabular}{llll}
\hline Treatment & Root DW $\left(\mathrm{g} \mathrm{plant}^{-1}\right)$ & Stem DW $\left.(\mathrm{g} \mathrm{plant})^{-1}\right)$ & Leaf DW $\left.(\mathrm{g} \mathrm{plant})^{-1}\right)$ \\
\hline WW & $20.36^{\mathrm{b}}$ & $29.56^{\mathrm{b}}$ & $33.49^{\mathrm{c}}$ \\
WW + CK75 & $21.23^{\mathrm{b}}$ & $30.88^{\mathrm{b}}$ & $35.34^{\mathrm{c}}$ \\
WW + CK150 & $23.20^{\mathrm{a}}$ & $34.98^{\mathrm{a}}$ & $40.10^{\mathrm{b}}$ \\
WW + CK225 & $23.55^{\mathrm{a}}$ & $36.69^{\mathrm{a}}$ & $43.43^{\mathrm{a}}$ \\
DS & $5.25^{\mathrm{e}}$ & $5.35^{\mathrm{d}}$ & $10.15^{\mathrm{f}}$ \\
DS + CK75 & $5.54^{\mathrm{de}}$ & $6.51^{\mathrm{cd}}$ & $12.19^{\mathrm{ef}}$ \\
DS + CK150 & $6.06^{\mathrm{d}}$ & $7.03^{\mathrm{cd}}$ & $13.32^{\mathrm{e}}$ \\
DS + CK225 & $7.98^{\mathrm{c}}$ & $9.18^{\mathrm{c}}$ & $17.56^{\mathrm{d}}$ \\
CV $(\%)$ & 6.69 & 8.38 & 7.15 \\
LSD $_{(0.05)}$ & 1.70 & 2.10 & 3.21 \\
\hline
\end{tabular}

Plants were exposed to drought stress at 26 DAE and continued up to 51 DAE (harvesting time) along with different concentrations of kinetin sprayed at 26 DAE and 35 DAE. Means followed by different alphabetical letter(s) within a column are significantly different from each other at $P<0.05$ according to Tukey's post hoc test. CK75, CK150 and CK225 represent 75, 150 and $225 \mathrm{mg} \mathrm{L}^{-1}$ cytokinin, respectively. DAE, days after emergence; DS, drought stress; DW, dry weight; WW, well-watered.

\subsection{Effects of CK on Stem Diameter and Leaf Senescence of Maize under Drought Stress}

Stem diameter and leaf senescence were determined at 23,30,37, 44 and 51 DAE to evaluate the effects of CK before and after drought stress on these two parameters (Figs. 1 and 2). Drought stressed plants showed a reduction of stem diameter by $12.10 \%$ to $30.90 \%$ but an increase of leaf senescence by $17.10 \%$ to $34.80 \%$ from 23 DAE to 51 DAE compared with WW plants. Accordingly, application of CK increased stem diameter but delayed leaf senescence in drought-stressed maize to some extent in an agedependent manner (Figs. 1 and 2). The percent reduction of stem diameter in drought-stressed plants was $5.6 \%$ to $24.7 \%$ relative to control plants upon application of CK (Fig. 1). Moreover, CK also increased stem diameter of WW plants by $0.8 \%$ to $8.8 \%$ relative to CK-devoid control plants (Fig. 1). In case of leaf senescence, we recorded that CK225 in non-stressed WW plants had the lowest leaf senescence rate (48.6\%) relative to control at 30 DAE (Fig. 2). However, CK150 and CK225 delayed the leaf senescence under drought stress condition, and the percent relative change was $-23.1 \%$ to $-37.8 \%$ as compared with WW plants (Fig. 2). Among different concentrations, CK225 was proved to be more efficient to reduce the effects of drought on both stem diameter and leaf senescence. 


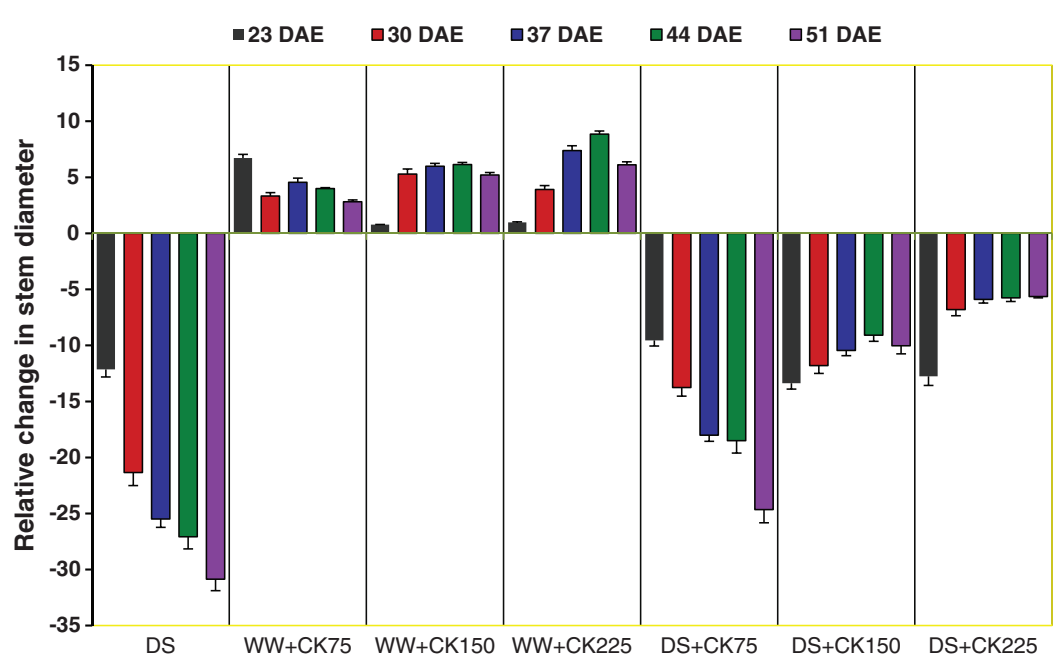

Figure 1: Effect of foliar-applied cytokinin (CK) on percent relative change of stem diameter relative to well-watered control maize plants at 23, 30, 37, 44 and 51 DAE. CK75, CK150 and CK225 represent 75, 150 and $225 \mathrm{mg} \mathrm{L}^{-1}$ kinetin. Bars indicate standard deviations $(n=6)$. DAE, days after emergence; DS, drought stress; WW, well-watered

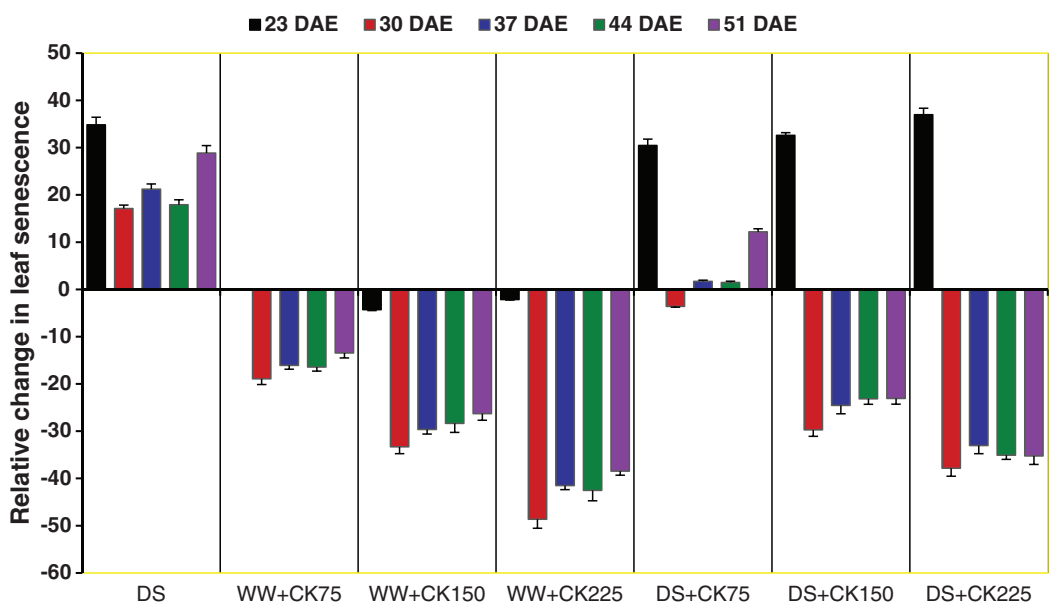

Figure 2: Effect of foliar-applied cytokinin (CK) on percent relative change of leaf senescence relative to well-watered control maize plants at 23, 30, 37, 44 and 51 DAE. CK75, CK150 and CK225 represent 75, 150 and $225 \mathrm{mg} \mathrm{L}^{-1}$ kinetin, respectively. Bars indicate standard deviations $(n=6)$. DAE, days after emergence; DS, drought stress; WW, well-watered

\subsection{Effects of CK on Gas Exchange Parameters in Maize under Drought Stress}

Net photosynthesis rate $(\mathrm{Pn})$, stomatal conductance (gs), intercellular $\mathrm{CO}_{2}$ concentration $(\mathrm{Ci})$, and transpiration rate $(\mathrm{Tr})$ were recorded at $51 \mathrm{DAE}$ to assess the effects of $\mathrm{CK}$ on these gas exchange characteristics of maize plants (Fig. 3). Exposure of maize plants to drought stress resulted in a significant reduction in photosynthetic attributes, including $\mathrm{Pn}$, gs, and $\operatorname{Tr}$ by $53.59 \%$, 42.27\%, and 85.12\%, respectively, whereas increment of $\mathrm{Ci}$ was observed by $12.24 \%$ when compared with WW plants. The application of exogenous $\mathrm{CK}$ in both control and drought-stressed plants improved the gas exchange attributes excluding $\mathrm{Ci}$ (Fig. 3). The higher the concentrations of CK, the more enhancements in gas 
exchange characteristics were recorded. The CK-application at CK225 following drought exposure resulted in an improvement of $\mathrm{Pn}, \mathrm{gs}$, and $\mathrm{Tr}$ by $39.94 \%, 27.73 \%$ and $121.36 \%$, respectively, and a reduction of Ci by $7.38 \%$ in comparison with those observed in drought-stressed only plants. This result indicated that CK at the higher dose $\left(225 \mathrm{mg} \mathrm{L}^{-1}\right)$ proved to be more effective than those of lower doses $\left(75\right.$ and $\left.150 \mathrm{mg} \mathrm{L}^{-1}\right)$ in improving gas exchange parameters under both normal and drought stress conditions (Fig. 3).
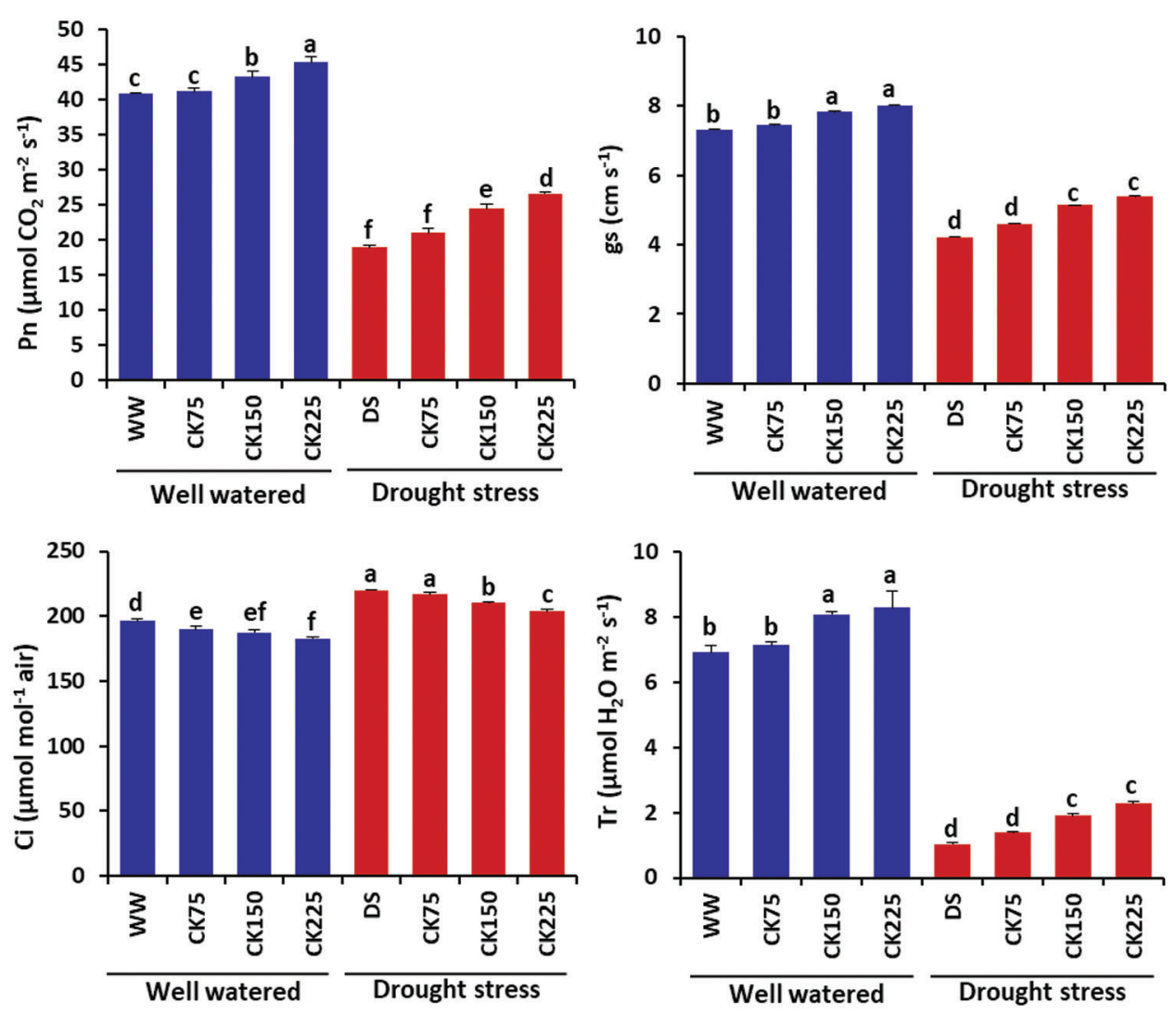

Figure 3: Effect of foliar-applied cytokinin (CK) on net photosynthesis rate (Pn), stomatal conductance (gs), internal $\mathrm{CO}_{2}$ concentration $(\mathrm{Ci})$ and transpiration rate $(\mathrm{Tr})$ in the leaves of maize plants at $51 \mathrm{DAE}$. Different alphabetical letters indicate statistically significant differences among the mean values at $P<0.05$ according to Tukey's post hoc test. CK75, CK150 and CK225 represent 75, 150 and $225 \mathrm{mg} \mathrm{L}^{-1}$ kinetin, respectively. Bars indicate standard deviations $(n=6)$. DAE, days after emergence; DS, drought stress; WW, well-watered

\subsection{Effects of CK on Water Status in Maize Plants under Drought Stress}

The effects of CK on plant water status in terms of relative water content (RWC), water saturation deficit (WSD), water uptake capacity (WUC), and electrolytic leakage (EL) were documented at 51 DAE in maize plants (Table 2). Drought-stressed plants showed a significant decrease in RWC (by 35.62\%) but an increase in SWD (by 83.36\%), WUC (by 135.34\%) and EL (by 29.69\%) when compared with control plants. The exogenously applied $\mathrm{CK}$ in both control and drought-stress plants improved plant water status, but the degree of improvement was much higher in drought-stressed plants (Table 2). Besides, the higher the concentrations of $\mathrm{CK}$, the more augmentations in plant water status were observed in control and drought-stressed plants. The application of CK at the higher dose (CK225) resulted in much improvement of RWC by $49.14 \%$, but reduction of WSD, WUC, and EL by $40.40 \%, 42.49 \%$ and $33.68 \%$, respectively in drought-stressed plants when compared with drought-stressed only plants. Our data also showed that 
CK225 was more effective than CK75 and CK150 in improving plant water status under both normal and drought stress conditions (Table 2).

Table 2: Effects of foliar-applied cytokinin (CK) on relative water content (RWC), water saturation deficit (WSD), water uptake capacity (WUC) and electrolytic leakage in the leaves of maize plants

\begin{tabular}{lllll}
\hline Treatment & $\begin{array}{l}\text { Relative water } \\
\text { content (RWC) (\%) }\end{array}$ & $\begin{array}{l}\text { Water saturation } \\
\text { deficit (WSD) }(\%)\end{array}$ & $\begin{array}{l}\text { Water uptake } \\
\text { capacity (WUC) }\end{array}$ & $\begin{array}{l}\text { Electrolytic } \\
\text { leakage (\%) }\end{array}$ \\
\hline WW & $70.07 \mathrm{c}$ & $29.93 \mathrm{~d}$ & $1.16 \mathrm{~d}$ & $24.59 \mathrm{~b}$ \\
$\mathrm{WW}+\mathrm{CK} 75$ & $74.29 \mathrm{~b}$ & $25.71 \mathrm{e}$ & $1.03 \mathrm{de}$ & $22.32 \mathrm{~cd}$ \\
$\mathrm{WW}+\mathrm{CK} 150$ & $77.78 \mathrm{a}$ & $22.22 \mathrm{f}$ & $0.91 \mathrm{e}$ & $19.62 \mathrm{de}$ \\
$\mathrm{WW}+\mathrm{CK} 225$ & $80.11 \mathrm{a}$ & $19.89 \mathrm{f}$ & $0.89 \mathrm{e}$ & $17.84 \mathrm{e}$ \\
$\mathrm{DS}$ & $45.12 \mathrm{f}$ & $54.88 \mathrm{a}$ & $2.73 \mathrm{a}$ & $31.89 \mathrm{a}$ \\
$\mathrm{DS}+\mathrm{CK} 75$ & $53.35 \mathrm{e}$ & $46.64 \mathrm{~b}$ & $2.39 \mathrm{~b}$ & $27.70 \mathrm{~b}$ \\
$\mathrm{DS}+\mathrm{CK} 150$ & $60.65 \mathrm{~d}$ & $39.35 \mathrm{c}$ & $1.86 \mathrm{c}$ & $23.87 \mathrm{~cd}$ \\
$\mathrm{DS}+\mathrm{CK} 225$ & $67.29 \mathrm{c}$ & $32.71 \mathrm{~d}$ & $1.57 \mathrm{c}$ & $21.15 \mathrm{~d}$ \\
$\mathrm{CV}(\%)$ & 2.85 & 5.63 & 11.85 & 7.78 \\
LSD $_{(0.05)}$ & 3.31 & 3.31 & 0.32 & 3.14 \\
\hline
\end{tabular}

Plants were exposed to drought stress at 26 DAE and continued up to 51 DAE (harvesting time) along with different concentrations of kinetin sprayed at $26 \mathrm{DAE}$ and 35 DAE. Means followed by different alphabetical letter(s) within a column are significantly different from each other at $P<0.05$ according to Tukey's post hoc test. CK75, CK150 and CK225 represent 75, 150 and $225 \mathrm{mg} \mathrm{L}^{-1}$ kinetin, respectively. DAE, days after emergence.

\subsection{Effects of CK on Biochemical Status in Maize Plants under Drought Stress}

The effects of CK on the proline, soluble sugars, malondialdehyde (MDA), and chlorophyll in the leaves of maize plants were observed at 51 DAE (Fig. 4). The drought-stressed maize plants experienced much elevation in proline (by 137.58\%), soluble sugars (by 73.95\%), and MDA (by 55.69\%) but a decline in total chlorophyll contents (by 56.41\%) compared with control plants. Both drought-stressed and control plants applied with CK displayed a reduction in proline, soluble sugar and MDA contents but an increase in total chlorophyll content. Such decreasing rate of proline, soluble sugar, and MDA and increasing rate of chlorophyll contents was much higher in drought-stressed plants if compared with control plants. Interestingly, a high concentration of CK (CK225) had more ameliorating effects by reducing the accumulations of proline, soluble sugar, and MDA and increasing chlorophyll content in both droughtstressed and control plants (Fig. 4). Exogenous application of CK225 to drought-stressed maize plants reduced proline, soluble sugars and MDA contents by $47.89 \%, 40.25 \%$, and $27.68 \%$, respectively, relative to drought-stressed only plants. Under non-stressed conditions, CK225 reduced the levels of proline, soluble sugars and MDA by $17.61 \%, 22.04 \%$ and $9.81 \%$, respectively, and increased total chlorophyll contents by $61.54 \%$ in comparison with control plants. Results indicated that CK at a higher dose (CK225) proved to be more effective than those of lower doses (CK75 and CK150) in positively modulating the biochemical parameters of maize plants under both normal and drought-stressed conditions (Fig. 4). 

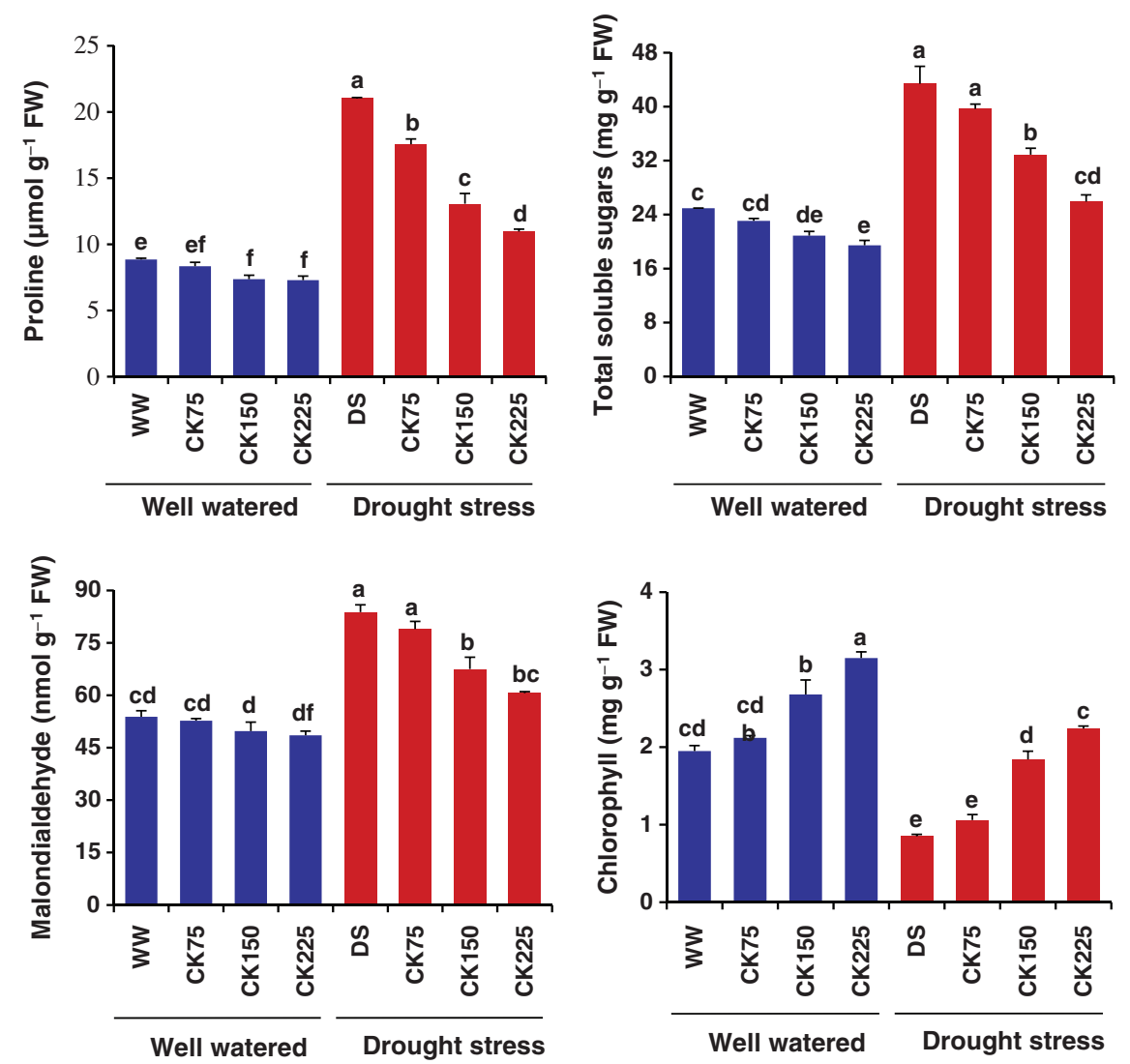

Figure 4: Effect of foliar-applied cytokinin (CK) on the levels of proline, soluble sugars, malondialdehyde (MDA) and total chlorophylls in the leaves of maize plants at 51 DAE. Different alphabetical letters indicate statistically significant differences among the mean values at $P<0.05$ according to Tukey's post hoc test. CK75, CK150 and CK225 represent 75, 150 and $225 \mathrm{mg} \mathrm{L}^{-1}$ kinetin, respectively. Bars indicate standard deviations $(n=6)$. DAE, days after emergence; DS, drought stress; WW, well-watered

\subsection{Comparative Responses Across Treatments}

Comparative heatmap analysis revealed two distinct clusters among parameters measured in this study (Fig. 5). Cluster 1 consisted of dry weights, Pn, Gs, Tr, RWC, total chlorophyll contents and stem diameter. Proline content, Ci, WUC, MDA, WSD, TSS, EL and leaf senescence were placed in Cluster 2. At the treatment levels, well-watered maize plants foliar sprayed with different doses of CK were clustered in the Group 1, while except CK225, drought-stressed maize plants with or without foliar application of CK placed in Group 2 (Fig. 5). However, DS + CK225 displayed significantly higher amelioration effects on drought stress, indicated by comparatively lower contribution of the traits of Cluster 2 and increase in the RWC and stem diameter and higher retention of chlorophyll contents assembled in the distinct Group 3 (Fig. 5).

\section{Discussion}

Drought, the most prominent threat to maize production, accelerates leaf senescence and chlorosis, leading to a decrease in photosynthesis, biomass production and yield potential of plants $[47,48]$. The exogenously applied CK is known to regulate plant growth and development by controlling several plant processes, including photosynthesis and osmoprotection, oxidative stress protection during drought-succession of 
plants $[49,50]$. The current study aimed at assessing the effectiveness of CK in alleviating drought adversities in commercially vital crop maize.

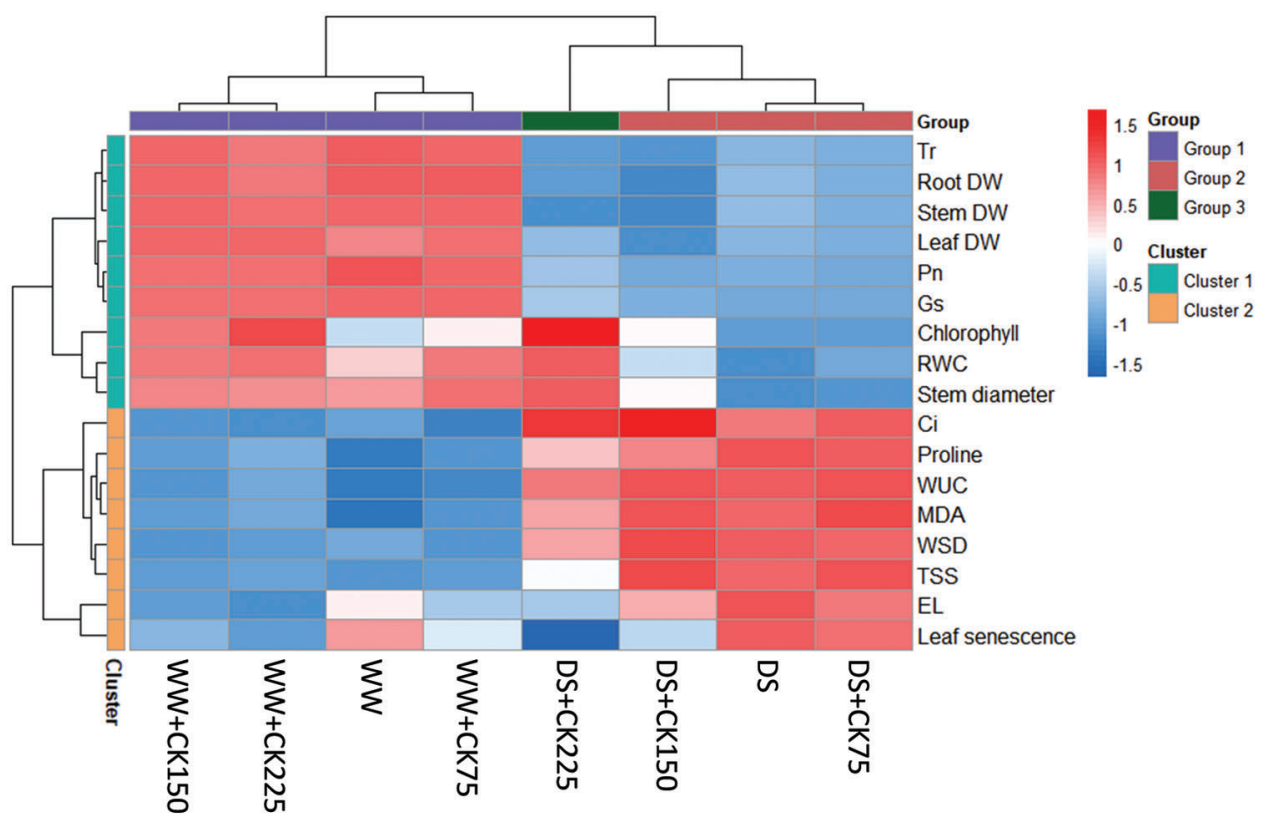

Figure 5: Heatmap and cluster analysis of growth and physio-biochemical attributes of maize plants grown under well-watered (WW) and drought-stress (DS) followed by treatment with different concentrations of cytokinin. CK75, CK150 and CK225 represent 75, 150 and $225 \mathrm{mg} \mathrm{L}^{-1}$ kinetin, respectively. DW, dry weight; Pn, net photosynthesis rate; Gs, stomatal conductance; Tr, transpiration rate; $\mathrm{Ci}$, intercellular $\mathrm{CO}_{2}$; RWC, relative water content; EL, electrolyte leakage; MDA, malondialdehyde; TSS, total soluble sugars; WUC, water uptake capacity; WSD, water saturation deficit

The benefits of foliar application of $\mathrm{CK}$ on stem diameter, leaf chlorophyll content, delay of leaf senescence, and greater photosynthesis rate were positively corelated with the biomass production in maize plants under drought stress conditions (Table 1; Figs. 1-3), as also observed by Akter et al. [13]. Application of exogenous CK might have enhanced the endogenous levels of CK, which later stimulated the overall performance of maize plants to overcome water-shortage caused negative effects on growth (Table 1). The CK-mediated enhancement of stem diameter attributed to the promotion of cell division [51]. The current study showed that CK application acted positively in reduction of leaf senescence and chlorophyll loss (Figs. 2 and 4). The reduction in chlorophyll concentration, damage of the photosynthetic machinery, and oxidative damage are all well-known consequences of natural or stressinduced leaf senescence [52]. Drought causes early leaf and flower senescence in plants by increasing the production of senescence-associated genes that code for cysteine proteases [53]. CK has been proved to be beneficial for drought adaptation of plants by delaying the leaf senescence, preventing protein breakdown, activating protein synthesis, and assembling nutrients from nearby tissues [54]. Liu et al. [55] reported that exogenously administered CK controlled rice flag leaf aging via regulating chlorophyll degradation, membrane deterioration, and senescence-associated gene expression.

Drought stress significantly depressed canopy and leaf gas exchanges to a varying degree, showing a greater reduction in Pn, gs and Tr of the maize plants (Fig. 3). These results are in agreement with the reports of Vitale et al. [56], Naeem et al. [57] and Ashraf et al. [58], who demonstrated that photosynthesis of drought stressed plants appeared to be reduced primarily because of stomatal closure 
and later by a reduction in photosynthetic capacity. High stomatal conductance is the prerequisite for an increase in $\mathrm{CO}_{2}$ fixation per unit of leaf area to allow a greater photosynthesis rate [59]. Under drought circumstances, the stomata remain closed for an extended length of time, reducing $\mathrm{CO}_{2}$ absorption and water loss to preserve plant water status [60,61]. The exogenous application of CK increased Pn, gs and Tr in maize plants grown under normal or drought stress conditions (Fig. 3), which is in conformity with the findings of $\mathrm{Wu}$ et al. [25] in eggplant under salinity stress. In the current study, we observed an increased Tr and gs in parallel with increased RWC in maize plants treated with CK. Our results suggest that CK helped maize plants to maintain an elevated Tr for enhancing Pn to support plant growth under water-shortage conditions. It is likely that CK did not play roles in water saving through the reduction of $\mathrm{Tr}$ in maize plants exposed to water-limited stress.

It is worth noting that understanding the current state of water relations is critical for better crop management in drought-prone locations. Among several water-related parameters, RWC is an important characteristic that used as an integrative indicator for dehydration tolerance [62-64]. A decrease in RWC due to drought resulted in a loss of turgor, which caused limited water availability for the cell division process in plants [65,66]. In this study, we observed that leaf RWC decreased during drought stress, but CK-treated plants showed a comparatively higher leaf RWC under both normal and water-limited conditions (Table 2), which supported the results of Chang et al. [67]. We also noticed that RWC gradually increased upon increasing the doses of CK in drought-affected maize plants (Table 2). This result suggested that CK positively regulated water status in maize plants to cope with the adverse effects of drought. The observed high WSD in drought-stressed maize plants indicated that drought stress caused a greater degree of water deficit, which corroborated the findings of Islam et al. [68] in mung bean, Chowdhury et al. [69] in French bean and Mahmud et al. [70] in potato. On the other hand, foliar application of CK greatly decreased the WSD in both well-watered and drought stress conditions (Table 2), indicating that CK application helped maize plants to preserve water status for better growth performance. WSD is inversely correlated with the RWC in leaves [71], which could be resulted from the adjustment of physiological traits like root structure and root density. It has been reported that shootdriven CK basipetally moved towards the roots, leading to the enlargement of the root system for foraging more area to absorb water under water-shortage conditions [72]. Thus, CK-induced modulation of root structure and growth can help plants maintain better water status to thrive under water deficit conditions [72]. However, WUC of drought-stressed plants was greater than that of control plants, suggesting that maize plants tried to compensate water deficiency by increasing WUC. On the contrary, application of CK reduced WUC in both control and drought-stressed plants (Table 2), implying that CK is more able to maintain internal water status rather than increasing WUC in maize plants.

Plants respond to drought stress by adopting different physiological and biochemical strategies. Plants accumulate various osmoprotectants to protect themselves from mild to severe water-deficit stress. Among the osmoprotectants, proline and soluble sugars are the two most widely studied organic solutes because of their considerable importance in conferring stress tolerance in plants under water-shortage conditions $[73,74]$. It is well documented that accumulation of proline acts not only in osmotic adjustment, but also participate in oxidative stress protection in plants [75-77]. Proline can also supply energy for growth and survival of plants, particularly under stressful conditions [78]. Thus, accumulation of proline refers to an important adaptation strategy of plants to overcome deleterious effects of abiotic stresses, including drought $[78,79]$. In the current study, drought stress in maize plants resulted in a considerable proline buildup (Fig. 4A), as was also documented in other plant species, including wheat and soybean facing water shortages $[12,80]$. However, foliar application of CK reduced proline content in the leaves of maize plants, suggesting that $\mathrm{CK}$ application did not require the accumulation of much proline to manage drought stress. It is likely that CK supplementation eased maize suffering from negative effects of drought, which resulted in decreased accumulation of proline. Indeed, proline is used as stress indicator, 
and its accumulation also corelated with the intensity of stress generated in plants under abiotic stress conditions, including drought $[12,81,82]$. Our results are in parallel with the earlier findings of Das et al. [83], who observed reduced accumulation of proline in CK-sprayed NaCl-stressed plants. We also observed significant increment of soluble sugar contents in drought-stressed maize plants (Fig. 4B), indicating that soluble sugars functioned in osmotic stress management under drought conditions [81]. However, application of CK lowered the accumulation of soluble sugars in a concentration dependent manner under drought stress conditions. This result was in agreement with the findings of Agarwal et al. [84] in callus cultures of cowpea and Yadav et al. [85] in Cicer, where they found kinetin as an osmotic adjustment stimulator. It has been reported that CK-overproducing transgenic rice $P_{S A R K}: I P T$ showed higher hexokinase activity and lower levels of soluble sugars like glucose and fructose than wild-type under water deficit conditions [86]. It is plausible that increased levels of CK rendered enhanced glycolysis of carbohydrates, thus depletion of soluble sugars, to supply adequate amounts of metabolites for facilitating high energy productions in response to drought.

Malondialdehyde is commonly used as an indicator of oxidative stress in plants under adverse environmental conditions. Lower MDA level indicates the higher antioxidant capacity in plants, thereby reflecting higher drought resistance as suggested by Izabela et al. [87] and Weng et al. [88]. In this study, MDA content significantly increased under drought condition in maize plant (Fig. 4C), which is in agreement with the findings of Sarafraz-Ardakani et al. [80]. According to their findings, MDA content was increased by $503 \%$ and $750 \%$ in drought-tolerant and drought-sensitive wheat cultivars, respectively. We observed that CK treatment lowered MDA contents in the leaves of maize plants in a concentrationdependent manner, and $\mathrm{CK}$ at $225 \mathrm{mg} \mathrm{L}^{-1}$ exhibited best performance in lowering MDA level. Heatmap analysis also showed that CK225 mitigated drought-stress principally by lowering MDA content, reducing electrolyte leakage and increasing RWC in the leaves of maize plant (Fig. 5). Current findings are in agreement with earlier report on creeping bent grass [67]. Our results suggest that CK might play an indirect role in the maintenance of antioxidant systems, which protected maize plants from droughtinduced oxidative damages [89]. Indeed, EL also significantly decreased upon application of CK to the drought-stressed maize plants (Table 2). These results suggest that CK supplementation was effective in reducing the membrane damage. The CK-mediated recovery from membrane injury and increase in cell viability was reported in wheat plants under PEG-induced drought stress conditions [16].

\section{Conclusions}

Drought stress resulted in a reduction of morpho-physiological attributes and growth performance of maize plants at the early developmental stage. On the other hand, application of exogenous CK to drought-exposed maize plants caused an improvement of growth, which was positively associated with better gas exchange and photosynthesis parameters, and water relation characters. The reduced levels of stress indicators like proline, MDA and electrolyte leakage upon supplementation of CK indicated that CK had a soothing effect in overcoming drought effects on maize plants. Taking together, CK application improved drought tolerance in maize, and $\mathrm{CK}$ at $225 \mathrm{mg} \mathrm{L}^{-1}$ (CK225) was shown to be the most beneficial in alleviating drought effects on maize plants. However, a further study is required to determine the precise dose of CK and mechanistic insight of CK-mediated drought tolerance in maize under field conditions.

Author Contributions: M.R.I. designed and supervised the experiment. M.S.I. performed the experiment, harvested plant materials and collected field data. N.A. oversaw experiment, analyzed data and drafted manuscript with input from M.R.I and M.G.M. M.M. performed biochemical analysis and analyzed data. M.R.I. and M.G.M wrote, revised and finalized the manuscript. 
Funding Statement: This research work was supported by the Ministry of Science and Technology, Government of Bangladesh. We also thank Bangladesh Agricultural Research Institute (BARI) for kindly providing the maize seeds for conducting the experiment.

Conflicts of Interest: The authors declare that they have no conflicts of interest.

\section{References}

1. Song, L., Jin, J., He, J. (2019). Effects of severe water stress on maize growth processes in the field. Sustainability, 11, 5086. DOI 10.3390/su11185086.

2. Daryanto, S., Wang, L., Jacinthe, P. A. (2016). Global synthesis of drought effects on maize and wheat production. PLoS One, 11, e0156362. DOI 10.1371/journal.pone.0156362.

3. Kim, W., Iizumi, T., Nishimori, M. (2019). Global patterns of crop production losses associated with droughts from 1983 to 2009. Journal of Applied Meteorology and Climatology, 58, 1233-1244. DOI 10.1175/JAMC-D-180174.1.

4. Aadhar, S., Mishra, V. (2011). On the occurrence of the worst drought in south Asia in the observed and future climate. Environmental Research Letters, 16, 024050. DOI 10.1088/1748-9326/abd6a6.

5. Li, X., Waddington, S. R., Dixon, J., Joshi, A. K., de Vicente, M. C. (2011). The relative importance of drought and other water-related constraints for major food crops in south asian farming systems. Food Security, 3, 19-33. DOI 10.1007/s12571-011-0111-x.

6. Hoque, M. A., Pradhan, B., Ahmed, N. (2020). Assessing drought vulnerability using geospatial techniques in northwestern part of Bangladesh. Science of the Total Environment, 705, 135957. DOI 10.1016/j. scitotenv.2019.135957.

7. Leng, G., Hall, J. (2019). Crop yield sensitivity of global major agricultural countries to droughts and the projected changes in the future. Science of the Total Environment, 654, 811-821. DOI 10.1016/j.scitotenv.2018.10.434.

8. Osakabe, Y., Osakabe, K., Shinozaki, K., Tran, L. S. P. (2014). Response of plants to water stress. Frontiers in Plant Science, 5, 86. DOI 10.3389/fpls.2014.00086.

9. Fahad, S., Bajwa, A. A., Nazir, U., Anjum, S. A., Farooq, A. et al. (2017). Crop production under drought and heat stress: Plant responses and management options. Frontiers in Plant Science, 8, 1147. DOI 10.3389/ fpls.2017.01147.

10. Salehi-Lisar, S. Y., Bakhshayeshan-Agdam, H. (2016). Drought stress in plants: Causes, consequences, and tolerance. In: Hossain, M., Wani, S., Bhattacharjee, S., Burritt, D., Tran, L. S. (Eds.). Drought stress tolerance in plants, vol. 1, pp. 1-16. Switzerland: Springer International Publishing.

11. Nadeem, M., Li, J., Yahya, M., Sher, A., Ma, C. et al. (2019). Research progress and perspective on drought stress in legumes: A review. International Journal of Molecular Sciences, 20, 2541. DOI 10.3390/ijms20102541.

12. Rahman, M., Mostofa, M. G., Keya, S. S., Rahman, A., Das, A. K. et al. (2021). Acetic acid improves drought acclimation in soybean: An integrative response of photosynthesis, osmoregulation, mineral uptake and antioxidant defense. Physiologiae Plantarum, 172, 334-350. DOI 10.1111/ppl.13191.

13. Akter, N., Islam, M. R., Karim, M. A., Hossain, T. (2014). Alleviation of drought stress in maize by exogenous application of gibberellic acid and cytokinin. Journal of Crop Science and Biotechnology, 17, 41-48. DOI 10.1007/s12892-013-0117-3.

14. Lamaoui, M., Jemo, M., Datla, R., Bekkaoui, F. (2018). Heat and drought stresses in crops and approaches for their mitigation. Frontiers of Chemistry, 6, 26. DOI 10.3389/fchem.2018.00026.

15. Llanes, A., Andrade, A., Alemano, S., Luna, V. (2016). Alterations of endogenous hormonal levels in plants under drought and salinity. American Journal of Plant Sciences, 7, 1357-1371. DOI 10.4236/ajps.2016.79129.

16. Kaur, A., Thind, S. K. (2018). Effects of cytokinins on membrane stability and cell viability of wheat crop under PEG-induced drought condition. Journal of Environmental Biology, 39, 1041-1046. DOI 10.22438/jeb/.

17. Kieber, J. J., Schaller, G. E. (2014). Cytokinins. The Arabidopsis Book, 12, e0168. DOI 10.1199/tab.0168. 
18. Pavlů, J., Novák, J., Koukalová, V., Luklová, M., Brzobohatý, B. et al. (2018). Cytokinin at the crossroads of abiotic stress signaling pathways. International Journal of Molecular Sciences, 19, 2450. DOI 10.3390/ ijms 19082450.

19. Hoang, X. L. T., Prerostova, S., Thu, N. B. A., Thao, N. P., Vankova, R. et al. (2021). Histidine kinases: Diverse functions in plant development and responses to environmental conditions. Annual Review of Plant Biology, 72, 297-323. DOI 10.1146/annurev-arplant-080720-093057.

20. Zwack, P. J., Rashotte, A. M. (2015). Interactions between cytokinin signaling and abiotic stress responses. Journal of Experimental Botany, 66, 4863-4871. DOI 10.1093/jxb/erv172.

21. Hai, N. N., Chuong, N. N., Tu, N. H. C., Kisiala, A., Hoang, X. L. T. et al. (2020). Role and regulation of cytokinins in plant response to drought stress. Plants, 9, 422. DOI 10.3390/plants9040422.

22. Zhao, Z., Andersen, S. U., Ljung, K., Dolezal, K., Miotk, A. et al. (2010). Hormonal control of the shoot stem-cell niche. Nature, 465, 1089-1092. DOI 10.1038/nature09126.

23. Su, Y. H., Liu, Y. B., Zhang, X. S. (2011). Auxin-cytokinin interaction regulates meristem development. Molecular Plant, 4, 616-625. DOI 10.1093/mp/ssr007.

24. Zhang, W., Swarup, R., Bennett, M., Schaller, G. E., Kieber, J. J. (2013). Cytokinin induces cell division in the quiescent center of the arabidopsis root apical meristem. Current Biology, 23, 1979-1989. DOI 10.1016/j. cub.2013.08.008.

25. Wu, X., Zhu, Z., Li, X., Zha, D. (2012). Effects of cytokinin on photosynthetic gas exchange, chlorophyll fluorescence parameters and antioxidative system in seedlings of eggplant (Solanum melongena L.) under salinity stress. Acta Physiologiae Plantarum, 34, 2105-2114. DOI 10.1007/s11738-012-1010-2.

26. de Moura, F. B., da, S., Vieira, M. R., do, N., Simões, A. et al. (2017). Participation of cytokinin on gas exchange and antioxidant enzymes activities. Indian Journal of Plant Physiology, 22, 16-29. DOI 10.1007/s40502-0170283-2.

27. Dong, H., Niu, Y., Kong, X., Luo, Z. (2009). Effects of early-fruit removal on endogenous cytokinins and abscisic acid in relation to leaf senescence in cotton. Plant Growth Regulation, 59, 93-101. DOI 10.1007/s10725-0099392-x.

28. Zwack, P. J., Rashotte, A. M. (2013). Cytokinin inhibition of leaf senescence. Plant Signaling \& Behavior, 8, e24737. DOI 10.4161/psb.24737.

29. Kiba, T., Kudo, T., Kojima, M., Sakakibara, H. (2011). Hormonal control of nitrogen acquisition: Roles of auxin, abscisic acid, and cytokinin. Journal of Experimental Botany, 62, 1399-1409. DOI 10.1093/jxb/erq410.

30. Krishnan, S., Laskowski, K., Shukla, V., Merewitz, E. B. (2013). Mitigation of drought stress damage by exogenous application of a non-protein amino acid $\gamma$-aminobutyric acid on perennial ryegrass. Journal of the American Society for Horticultural Science, 138, 358-366. DOI 10.21273/JASHS.138.5.358.

31. Xu, L., Han, L., Huang, B. (2011). Antioxidant enzyme activities and gene expression patterns in leaves of kentucky bluegrass in response to drought and post-drought recovery. Journal of the American Society for Horticultural Science, 136, 247-255. DOI 10.21273/JASHS.136.4.247.

32. Koprna, R., Humplík, J. F., Špíšek, Z., Bryksová, M., Zatloukal, M. et al. (2021). Improvement of tillering and grain yield by application of cytokinin derivatives in wheat and barley. Agronomy, 11, 67. DOI 10.3390/ agronomy 11010067.

33. Raza, M. A. S., Zaheer, M. S., Saleem, M. F., Khan, I. H., Ahmad, S. et al. (2020). Drought ameliorating effect of exogenous applied cytokinin in wheat. Pakistan Journal of Agricultural Sciences, 57, 725-733. DOI 10.21162/ PAKJAS/20.8183.

34. Islam, M. R., Hasan, M., Akter, N., Akhtar, S. (2021). Cytokinin and gibberellic acid alleviate the effect of waterlogging in mungbean (Vigna radiata L. wilczek). Journal Clean Was, 5, 21-26. DOI 10.26480/ jcleanwas.01.2021.21.26.

35. Latef, A. A. A., Hasanuzzaman, M., Tahjib-Ul-Arif, M. (2021). Mitigation of salinity stress by exogenous application of cytokinin in faba bean (Vicia faba L.). Notulae Botanicae Horti Agrobotanici Cluj-Napoca, 49, 12192. DOI 10.15835/nbha49112192. 
36. BARC (2012). Fertilizer Recommendation Guide. Bangladesh Agricultural Research Council (BARC), Farmgate, Dhaka.

37. Borras, L., Westgate, M. E., Otegu, M. E. (2003). Control of kernel weight and kernel water relations by postflowering source-sink ratio in maize. Annals of Botany, 91, 857-867. DOI 10.1093/aob/mcg090.

38. Schonfeld, M. A., Johnson, R. C., Carver, B. F., Mornhinweg, D. W. (1988). Water relations in winter wheat as drought resistance indicator. Crop Science, 28, 526-531. DOI 10.2135/cropsci1988.0011183X002800030021x.

39. Sangakkara, H. R., Hartwig, U. A., Nosberger, J. (1996). Response of root branching and shoot water potential of French beans (Phaeseolus valgaris L.) to soil moisture and fertilizer potassium. Journal of Agronomy and Crop Science, 177, 165-173. DOI 10.1111/j.1439-037X.1996.tb00234.x.

40. Witharn, F. H., Blydes, D. F., Devlin, R. M. (1971). Experiment in plant physiology. USA: Van Norst and Reinhold Co.

41. Bates, L. S., Waldran, R. P., Teare, I. D. (1973). Rapid determination of free proline for water stress studies. Plant and Soil, 39, 205-208. DOI 10.1007/BF00018060.

42. Kirankumari, S. P., Sridevi, V., Lakshmi, M. V. V. C. (2012). Studies on effect of salt stress on some medicinal plants. International Journal of Computational Engineering Research, 2, 143-149.

43. Heath, R. L., Packer, L. (1968). Photoperoxidation in isolated chloroplasts. I. Kinetics and Stoichiometry of Fatty Acid Peroxidation. Archives of Biochemistry and Biophysics, 125, 189-198. DOI 10.1016/0003-9861(68)90654-1.

44. Kocheva, K., Georgiev, G. (2003). Evaluation of the reaction of two contrasting barley (Hordeum vulgare L.) cultivars in response to osmotic stress with PEG 6000. Bulgarian Journal of Plant Physiology, 49, 290-294.

45. Russel, D. F., Eisensmith, S. P. (1983). MSTAT-C, pp.1-54. USA: Michigan State University, Crop and Soil Science Department.

46. Kolde, R. (2019). Pheatmap: Pretty Heatmaps. R Package Version 1.0.12. https://rdrr.io/cran/pheatmap/.

47. Ali, Q., Ashraf, M. (2011). Induction of drought tolerance in maize (Zea mays L.) due to exogenous application of trehalose: Growth, photosynthesis, water relations and oxidative defense mechanism. Journal of Agronomy and Crop Science, 197, 258-271. DOI 10.1111/j.1439-037X.2010.00463.x.

48. Jain, M., Kataria, S., Hirve, M., Prajapati, R. (2019). Water deficit stress effects and responses in maize. In: Hasanuzzaman, M., Hakeem, K., Nahar, K., Alharby, H. (Eds.), Plant abiotic stress tolerance, pp. 129-151. Switzerland: Springer International Publishing.

49. Depuydt, S., Van Praet, S., Nelissen, H., Vanholme, B., Vereecke, D. (2016). How plant hormones and their interactions affect cell growth. In: Rose, R.J. (Eds.), Molecular cell biology of the growth and differentiation of plant cells, pp. 174-195. USA: CRC Press.

50. Prerostova, S., Dobrev, P. I., Gaudinova, A., Knirsch, V., Körber, N. et al. (2018). Cytokinins: Their impact on molecular and growth responses to drought stress and recovery in arabidopsis. Frontiers in Plant Science, 9, 655. DOI 10.3389/fpls.2018.00655.

51. Kaya, C., Tuna, A. L., Okant, A. M. (2010). Effect of foliar applied kinetin and indole acetic acid on maize plants grown under saline conditions. Turkish Journal of Agriculture and Forestry, 34, 529-538. DOI 10.3906/tar-0906-173.

52. Hönig, M., Plíhalová, L., Husičková, A., Nisler, J., Doležal, K. (2018). Role of cytokinins in senescence, antioxidant defence and photosynthesis. International Journal of Molecular Sciences, 19, 4045. DOI 10.3390/ ijms19124045.

53. Botha, A. M., Kunert, K. J., Cullis, C. A. (2017). Cysteine proteases and wheat (Triticum aestivum L.) under drought: A still greatly unexplored association. Plant, Cell \& Environment, 40, 1679-1690. DOI 10.1111/ pce.12998.

54. Dwivedi, S. K., Kumar, S., Mondal, S., Malviya, N., Dubey, R. (2014). Physiological basis of cytokinin induced drought tolerance in wheat (Triticum aestivum L.). Journal of AgriSearch, 1, 139-144.

55. Liu, L., Li, H. X., Zeng, H. L., Cai, Q. S., Zhou, X. et al. (2016). Exogenous jasmonic acid and cytokinin antagonistically regulate rice flag leaf senescence by mediating chlorophyll degradation, membrane deterioration, and senescence-associated genes expression. Journal of Plant Growth Regulation, 35, 366-376. DOI 10.1007/s00344-015-9539-0. 
56. Vitale, L., di Tommasi, P., Arena, C., Riondino, M., Forte, A. et al. (2009). Growth and gas exchange response to water shortage of a maize crop on different soil types. Acta Physiologiae Plantarum, 31, 331-341. DOI 10.1007/ s11738-008-0239-2.

57. Naeem, M. S., Jin, Z. L., Wan, G. L., Liu, D., Liu, H. B. et al. (2010). 5-Aminolevulinic acid improves photosynthetic gas exchange capacity and ion uptake under salinity stress in oilseed rape (Brassica napus L.). Plant and Soil, 332, 405-415. DOI 10.1007/s11104-010-0306-5.

58. Ashraf, M., Harris, P. J. C. (2013). Photosynthesis under stressful environments: An overview. Photosynthetica, 51, 163-190. DOI 10.1007/s11099-013-0021-6.

59. Raines, C., Kramer, D. M., Lawson, T. (2012). Improving yield by exploiting mechanisms underlying natural variation of photosynthesis. Current Opinion in Biotechnology, 23, 215-220. DOI 10.1016/j.copbio.2011.12.012.

60. Sausen, T. L., Rosa, L. M. G. (2010). Growth and carbon assimilation limitations in Ricinus communis (Euphorbiaceae) under soil water stress conditions. Acta Botanica Brasilica, 24, 648-654. DOI 10.1590/S010233062010000300008.

61. Pan, X., Lada, R. R., Caldwell, C. D., Falk, K. C. (2011). Water-stress and N-nutrition effects on photosynthesis and growth of Brassica carinata. Photosynthetica, 49, 309-315. DOI 10.1007/s11099-011-0031-1.

62. Arjenaki, F. G., Jabbari, R., Morshedi, A. (2012). Evaluation of drought stress on relative water content, chlorophyll content and mineral elements of wheat (Triticum aestivum L.) varieties. International Journal of Agriculture and Crop Sciences, 4, 726-729.

63. Uzildaya, B., Turkan, I., Sekmen, A. H., Ozgur, R., Karakaya, H. C. (2012). Comparison of ROS formation and antioxidant enzymes in Cleome gynandra (C4) and Cleome spinosa (C3) under drought stress. Plant Science, 182, 59-70. DOI 10.1016/j.plantsci.2011.03.015.

64. Mohi-Ud-Din, M., Hossain, M. A., Rohman, M. M., Uddin, M. N., Haque, M. S. et al. (2021). Multivariate analysis of morpho-physiological traits reveals differential drought tolerance potential of bread wheat genotypes at the seedling stage. Plants, 10, 879. DOI 10.3390/plants10050879.

65. Sanchez-Rodriguez, E., Rubio-Wilhelmi, M., Cervilla, L. M., Blasco, B., Rios, J. J. et al. (2010). Genotypic differences in some physiological parameters symptomatic for oxidative stress under moderate drought in tomato plants. Plant Science, 178, 30-40. DOI 10.1016/j.plantsci.2009.10.001.

66. Khan, M. S. A., Karim, M. A., Mahmud, A. A., Parveen, S., Bazzaz, M. M. et al. (2015). Plant water relations and proline accumulations in soybean under salt and water stress environment. Journal of Plant Sciences, 3, 272-278. DOI 10.11648/J.JPS.20150305.15.

67. Chang, Z., Liu, Y., Dong, H., Teng, K., Han, L. et al. (2016). Effects of cytokinin and nitrogen on drought tolerance of creeping bentgrass. PLoS One, 11, e0154005. DOI 10.1371/journal.pone.0154005.

68. Islam, M. S., Karim, M. A., Haque, M. M., Hamid, A. (2010). Effect of benzylaminopurine on growth response and water status of mungbean [Vigna radiata (L.) Wilczek] under water deficit conditions. Journal of Agriculture and Environmental Sciences, 1, 31-39.

69. Chowdhury, A. K., Karim, M. A., Haque, M. M., Khaliq, Q. A., Ahmed, J. U. et al. (2010). Effect of water stress on plant water status of French bean (Phaseolus vulgais L.). Indian Journal of Plant Physiology, 15, 131-136.

70. Mahmud, A. A., Hossain, M., Bazzaz, M., Khan, S. A., Hossain, A. et al. (2014). Tuber yield, tuber quality and plant water status of potato under drought and well-watered condition. Global Journal of Science Frontier Research, 14, 101-107.

71. Park, J., Lee, Y., Martinoia, E., Geisler, M. (2017). Plant hormone transporters: What we know and what we would like to know. BMC Biology, 15, 93. DOI 10.1186/s12915-017-0443-x.

72. Malinowska, K. M., Myśków, B., Czyczyło-Mysza, I., Góralska, M. (2018). Study on changes and relationships of physiological and morphological parameters of rye subjected to soil drought stress. Acta Agrophysica, 25, 261275. DOI 10.31545/aagr/93584.

73. Shi, C. H., Dong, B. D., Qiao, Y., Li, Y. X. (2010). Physiological regulation of high transpiration efficiency in winter wheat under drought conditions. Plant, Cell \& Environment, 56, 340-347. DOI 10.17221/PSE.

74. Sumera, I., Asghari, B. (2010). Effect of drought and abscisic acid application on the osmotic adjustment of four wheat cultivars. Journal of the Chemical Society of Pakistan, 32, 13-19. 
75. de Campos, M. K. F., de Carvalho, K., de Souza, F. S., Marur, C. J., Pereira, L. F. P. et al. (2011). Drought tolerance and antioxidant enzymatic activity in transgenic "Swingle" citrumelo plants over-accumulating proline. Environmental and Experimental Botany, 72, 242-250. DOI 10.1016/j.envexpbot.2011.03.009.

76. Špoljarević, M., Agić, D., Lisjak, M., Gumze, A., Wilson, I. D. et al. (2011). The relationship of proline content and metabolism on the productivity of maize plants. Plant Signaling \& Behavior, 6, 251-257. DOI 10.4161/ psb.6.2.14336.

77. Cvikrová, M., Gemperlová, L., Dobrá, J., Martincová, O., Prásil, I. T. et al. (2012). Effect of heat stress on polyamine metabolism in proline-over-producing tobacco plants. Plant Science, 182, 49-58. DOI 10.1016/j. plantsci.2011.01.016.

78. Dar, M. I., Naikoo, M. I., Rehman, F., Naushin, F., Khan, F. A. (2016). Proline accumulation in plants: Roles in stress tolerance and plant development. In: Iqbal, N., Nazar, R. (Eds.), Osmolytes and plants acclimation to changing environment: Emerging omics technologies, pp. 155-166. India: Springer.

79. Hayat, S., Hayat, Q., Alyemeni, M. N., Wani, A. S., Pichtel, J. et al. (2012). Role of proline under changing environments. Plant Signaling \& Behavior, 7, 1456-1466. DOI 10.4161/psb.21949.

80. Sarafraz-Ardakani, M. R., Khavari-Nejad, R. A., Moradi, F., Najafi, F. (2014). Abscisic acid and cytokinin-induced osmotic and antioxidant regulation in two drought-tolerant and drought-sensitive cultivars of wheat during grain filling under water deficit in field conditions. Notulae Scientia Biologicae, 6, 354-362. DOI 10.15835/nsb639301.

81. Mohammadkhani, N., Heidari, R. (2008). Drought-induced accumulation of soluble sugars and proline in two maize varieties. World Applied Sciences Journal, 3, 448-453.

82. Mostofa, M. G., Seraj, Z. I., Fujita, M. (2015). Interactive effects of nitric oxide and glutathione in mitigating copper toxicity of rice (Oryza sativa L.) seedlings. Plant Signaling \& Behavior, 10, e991570. DOI 10.4161/ 15592324.2014.991570.

83. Das, C., Sengupta, T., Chattopadhyay, S., Setua, M., Das, N. K. et al. (2002). Involvement of kinetin and spermidine in controlling salinity stress in mulberry (Morus alba L. cv. S-1). Acta Physiologiae Plantarum, 24, 53-57. DOI 10.1007/s11738-002-0021-9.

84. Agarwal, R. K., Gupta, S. C. (1995). Plant growth substances as osmoregulants under salt stress in callus cultures of cowpea. Indian Journal of Plant Physiology, 38, 325-327.

85. Yadav, N., Gupta, V., Yadav, V. K. (1997). Role of benzyladenine and gibberellic acid in alleviating water-stress effect in gram (Cicer arietinum). Indian Journal of Agricultural Sciences, 67, 381-387.

86. Reguera, M., Peleg, Z., Abdel-Tawab, Y. M., Tumimbang, E. B., Delatorre, C. A. et al. (2013). Stress-induced cytokinin synthesis increases drought tolerance through the coordinated regulation of carbon and nitrogen assimilation in rice. Plant Physiology, 163, 1609-1622. DOI 10.1104/pp.113.227702.

87. Izabela, M., Ilona, C. M., Edyta, S., Maria, F., Stanisław, G. et al. (2013). Impact of osmotic stress on physiological and biochemical characteristics in drought-susceptible and drought-resistant wheat genotypes. Acta Physiologiae Plantarum, 35, 451-461. DOI 10.1007/s11738-012-1088-6.

88. Weng, M., Cui, L., Liu, F., Zhang, M., Shan, L. et al. (2015). Effects of drought stress on antioxidant enzymes in seedlings of different wheat genotypes. Pakistan Journal of Botany, 47, 49-56.

89. Stoparić, G., Maksimović, I. (2008). The effect of cytokinins on the concentration of hydroxyl radicals and the intensity of lipid peroxidation in nitrogen deficient wheat. Cereal Research Communications, 36, 601-609. DOI 10.1556/CRC.36.2008.4.9. 